\title{
Early unemployment can contribute to adult health problems: results from a longitudinal study of school leavers
}

\section{A Hammarström, U Janlert}

See end of article for authors' affiliations

Correspondence to: Dr A Hammarström, Family Medicine, Department of Public Health and Clinical Medicine, Umeå University, SE-901 85 UMEÅ, Sweden; anne.hammarstrom@ fammed.umu.se

Accepted for publication 19 October 2001
Study objective: To investigate the long term effects of early unemployment (a total of more than half a year of unemployment between the ages of 16 and 21) on health behaviour and psychological and somatic symptoms.

Design: A 14 year follow up of a cohort of school leavers was conducted from 1981 to 1995. Information was collected by questionnaires.

Setting: An industrial town in northern Sweden.

Participants: The original cohort was defined as all pupils in a middle sized municipality in the last year of compulsory school at age $16(n=1083)$. The participants were followed up between the ages of 16 and 30 . The analysis included $96 \%$ of the original sample, 547 men and 497 women

Main results: After controlling for initial health behaviour and symptoms as well as for working class background and late unemployment, early unemployment among young men and women showed a significant explanatory effect on smoking, psychological symptoms and-among men only-somatic symptoms after a follow up of 14 years. No correlation was found between early unemployment and late excess alcohol consumption.

Conclusions: Early unemployment can contribute to adult health problems. Thus, youth unemployment constitutes a significant public health problem, which to a certain extent remains in adult age.
$\mathrm{T}$ he short-term consequences of unemployment among young people have been well documented in literature with regard to psychological ill health, ${ }^{1-3}$ somatic ill health, ${ }^{4}$ alcohol consumption, ${ }^{5}$ and smoking. ${ }^{6}$ However, one of the crucial questions in unemployment research is whether unemployment has only a short-term effect, or if there also is an effect many years after the unemployment has come to an end. This question has a special interest within youth unemployment as work and working life is said to have a fundamental importance for the socialisation of young men and women. $^{7}$

Only a few longitudinal studies have investigated the problem of long term effects of unemployment. ${ }^{8-12}$ In most cases a relatively short period of unemployment at the beginning of a long observation period has been the basis for classifying a person as unemployed or not unemployed. This makes the relations between unemployment and health hard to illuminate. ${ }^{13}$ Besides these studies have had a narrow focus, for example on mortality. ${ }^{14}{ }^{15}$ Few studies have had the possibility to follow up a cohort continuously and correlate outcome measures with unemployment. The British birth cohort study concluded that prolonged unemployment between the ages of 16 and 27 seemed to have a long term effect (after control for health at school as well as socioeconomic background variables) on young men's health. ${ }^{16}$ However, the study was performed on men only and the health indicators used did not specify separate effects on health behaviour, psychological or somatic health.

The aim of this long term follow up study of young men and women has been to analyse possible effects of early unemployment on adult health behaviour and health symptoms.

\section{METHOD}

In a prospective cohort study all 1083 school leavers from compulsory school in an industrialised town in the north of
Sweden were followed up for 14 years. The cohort of school leavers were 16 years at the beginning of the study and were followed up independently of their activity after compulsory school (future studies, work, etc) until the age of 30 . The attrition rate was extremely low. Of the original 1083 pupils in the sample, 1080 were reached in the first survey and 1068 (98.6\% of the original sample) participated in at least two of the surveys-for 1044 participants (96\%) complete data from all four surveys are available (547 men and 497 women). Health behaviour and symptom complaints were monitored from the last year in compulsory school in 1981, when the pupils were 16 years old, to the age of 30 (in 1995).

\section{Data collection}

Data were collected by group questionnaires-at age 16 and 18 during school hours and at age 21 and 30 the participants were invited to reunions with their former classmates. Those who could not attend these reunions (and those at age 18 who had finished school) received a mailed questionnaire. Personal or telephone interviews were performed with participants who did not fill in the questionnaire (because of reading and writing difficulties, etc), in which the interviewer read the questions and response categories exactly as written in the mailed questionnaire.

The measures used in this study of somatic and psychological health as well as of health behaviour have been validated in previous research. ${ }^{17-19}$

The questions in focus in this study (smoking, alcohol, somatic and psychological health, and unemployment) have had the same wording throughout the whole period studied.

\section{Unemployment measures}

The data on the length of unemployment were taken from a specially constructed battery of questions where the participants were asked to report how many months and weeks they 
Table 1 Number of persons and mean unemployment (mean=weeks per year, SD=standard deviation) for persons in the different employment groups

\begin{tabular}{|c|c|c|c|c|c|c|c|c|c|c|c|c|}
\hline \multirow{4}{*}{$\begin{array}{l}\text { Employment } \\
\text { group }\end{array}$} & & & & & \multicolumn{8}{|c|}{ Mean unemployment in weeks per year } \\
\hline & \multicolumn{4}{|c|}{ Number of persons } & \multicolumn{4}{|c|}{ Age 16-21 } & \multicolumn{4}{|c|}{ Age $22-30$} \\
\hline & \multicolumn{2}{|l|}{ Men } & \multicolumn{2}{|c|}{ Women } & \multicolumn{2}{|l|}{ Men } & \multicolumn{2}{|c|}{ Women } & \multicolumn{2}{|l|}{ Men } & \multicolumn{2}{|c|}{ Women } \\
\hline & $\mathrm{N}$ & $\%$ & $\mathrm{~N}$ & $\%$ & Mean & SD & Mean & SD & Mean & SD & Mean & SD \\
\hline Early & 70 & 12.8 & 68 & 13.7 & 10.9 & 6.8 & 9.0 & 6.7 & 12.1 & 11.8 & 6.7 & 8.5 \\
\hline Late & 111 & 20.3 & 89 & 17.9 & 1.0 & 1.3 & 1.1 & 14.0 & 14.0 & 8.7 & 14.0 & 9.1 \\
\hline Reference & 366 & 66.9 & 340 & 68.4 & 0.6 & 1.1 & 0.6 & 1.1 & 0.7 & 1.7 & 1.0 & 1.9 \\
\hline
\end{tabular}

were unemployed, employed, studying, or participating in labour market programmes since the last follow up.

In the results section we were contrasting three types of employment patterns, defined in the following way:

- Early unemployment: $>0.5$ years in total of unemployment between the ages of 16 and 21 , irrespective of later unemployment.

- Late unemployment: > 1.5 years in total of unemployment between the ages of 22 and 30 with unemployment $<0.5$ years between the ages of 16 and 21

- Reference group: Not included in any of the unemployment groups above-that is, $<0.5$ years of unemployment between the ages of 16 and 21 and $<1.5$ years of unemployment between the ages of 22 and 30 .

During the study period, unemployment was actively combated in Sweden with extensive labour market programmes for especially young people with the goal that nobody should be continuously unemployed for more than a certain period (six months for young people and one year for adults). Therefore, we defined unemployment in our study from the summarised unemployment experience. For the early unemployment group, we used a common definition of long term unemployment (six months). ${ }^{20}$

\section{Smoking}

Smoking was defined as current daily smoking according to the questionnaire. Those who never had smoked, had smoked occasionally or had stopped smoking early were considered as non-smokers.

\section{Alcohol consumption}

The amount of alcohol consumed was estimated as per annum consumption with the help of a frequency-quantity form. The volume of different alcoholic beverages was converted into decilitres of pure alcohol. Those with alcohol consumption above the 75th centile were considered as high alcohol consumers. Different cut off points have been used for men and women because of large differences in total amount of alcohol consumption.

\section{Somatic symptoms}

A composite index of somatic complaints was constructed, consisting of 17 different somatic symptoms on a three grade scale-from 0 (no problems) to 2 (serious problems). The questions dealt with current symptoms during the past 12 months: headache, weight problems, gastric complaints, problems with locomotive apparatus, infections, accidental injuries, allergies, etc. All items are shown in the appendix. The summarised index, with a theoretical range from 0 to 34 was dichotomised at the 75th centile and the proportion over that cut off point has been presented as those with somatic symptoms.

\section{Psychological symptoms}

In a similar manner a composite index of psychological symptoms was constructed, consisting of nervous and depressive symptoms on a four grade scale-from 0 (never) to 3 (constantly). The nervous component of the psychological index consisted of five items about restlessness, lack of concentration, worries, palpitation, and anxiety, and their frequency during the past 12 months. The depressive component of the psychological index consisted of two questions regarding depression and sleeping problems (see appendix). This index (range 0 to 21 ) was also dichotomised at the 75 th centile and the proportion over that cut off point has been presented as those with psychological symptoms.

\section{Working class background}

On the basis of the baseline questionnaire at age 16 the participants were ascribed to working class background if their fathers were blue collar workers or, if they lived with their mothers only, their mothers were blue collar workers. Otherwise they were classified as not having a working class background.

\section{Long term effects}

To analyse the possible long term effects of early unemployment we have used the inherent quality of the longitudinality in our study to illustrate the difference between the two contrasting explanatory concepts-“selection" and "exposure". "Selection" is the phenomenon that a group, already at the start of the study and before any unemployment could be possible, shows a higher value of the studied characteristics than the reference group. Unfavourable health behaviour at the end of the study could thus be explained by the fact that the person already showed this unfavourable health behaviour (for example, smoking) at the start of the study. "Exposure" points to the fact that the unfavourable health behaviour is the consequence of exposure to unemployment, either already during the first part of the study (aged 16-21) or only during the second part (aged 22-30). Possible exposure and selection effects are illustrated both in the graphs and in the logistic regression analyses.

\section{Statistical methods}

The frequency of the different health habits and symptoms were graphically described for the different employment groups. The $\chi^{2}$ for trend (Mantel extension) was used to test for linear correlation. The effects of selection and exposure were estimated with logistic regression technique. A p value $<0.05$ for test for trend and a confidence interval of $95 \%$ for odds ratio were chosen to be statistically significant.

The study was approved by the Research Ethics Committees at Uppsala and Umeå Universities.

\section{RESULTS}

Unemployment in the different unemployment groups Table 1 shows the number of persons in each of the unemployment groups and their mean annual unemployment 
Reference group

A Early unemployment

- Late unemployment

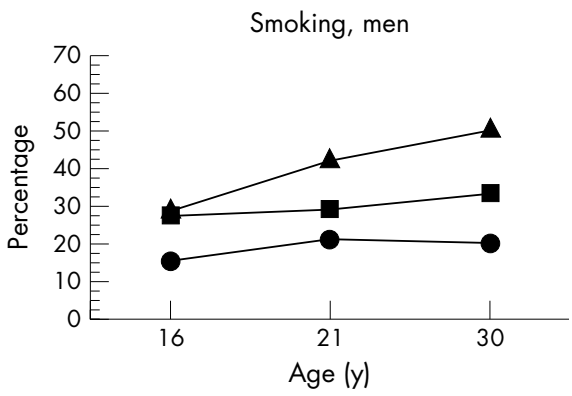

Excess alcohol, men

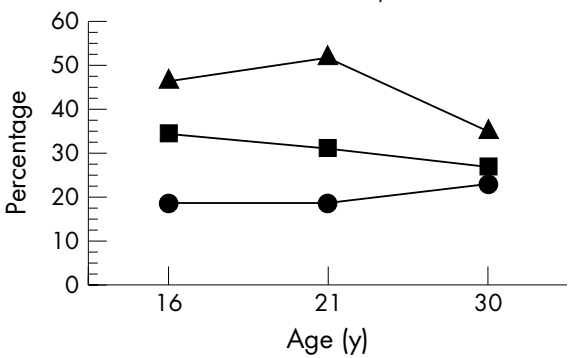

Somatic symptoms, men

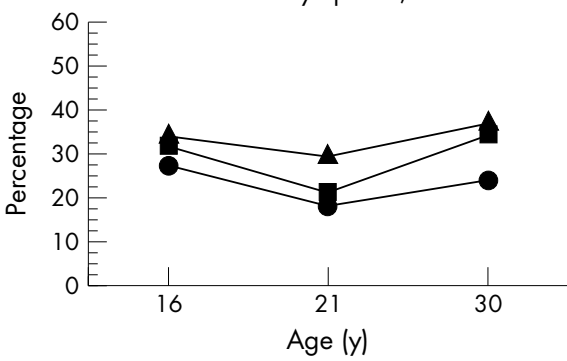

Psychological symptoms, men

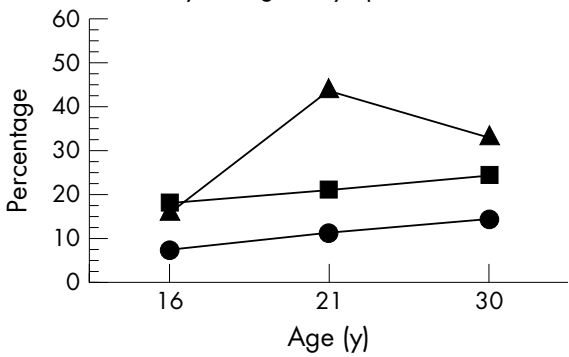

Figure 1 Frequencies of daily smoking (yes), excess alcohol consumption ( $>75$ th centile), somatic and psychological symptoms (>75th centile) at differences ages among men and women in three employment groups.
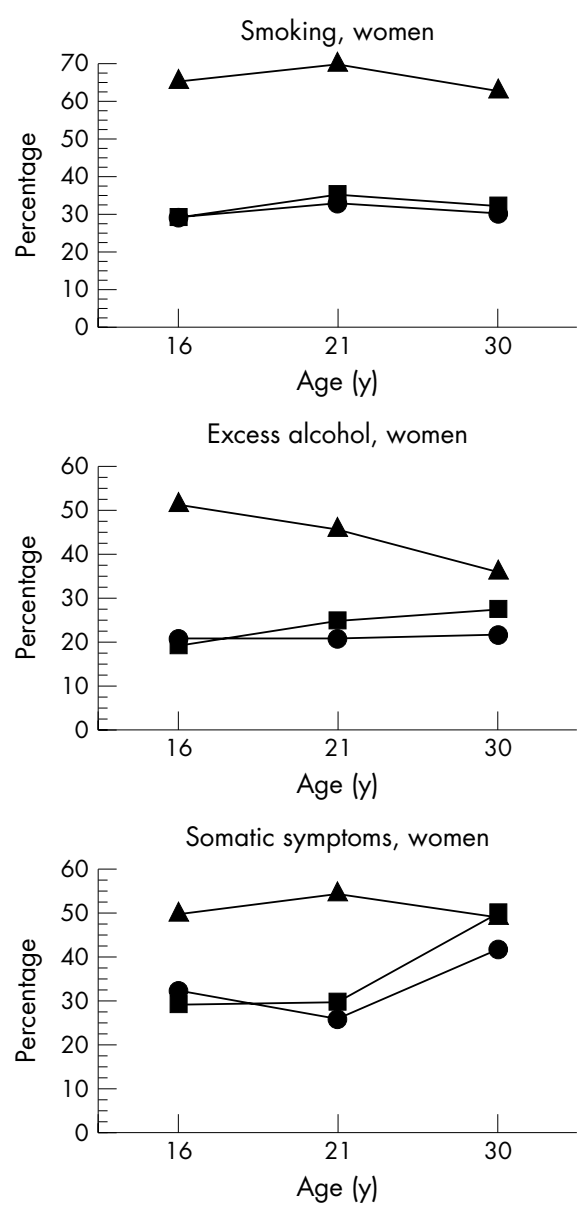

Psychological symptoms, women

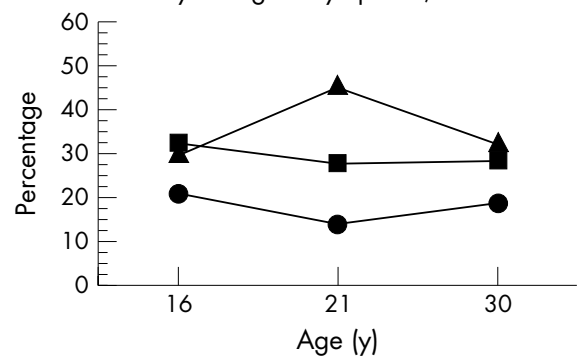

at age 16-21 (the early unemployment period) and at age 22-30 (the late unemployment period).

The group with early unemployment showed a 10-fold higher unemployment level during the first period (age 16-21) compared with both the late unemployment (age 22-30) and the reference group. Even in the second period they had a higher level than the references. The group with late unemployment showed much higher unemployment in the late period. The differences between the sexes were small with the exception of unemployment when aged 22-30 in the early unemployed group; here the men had higher unemployment than during the period 16-21 years of age.

\section{Long term changes}

One way of illustrating the findings is to show the development of habits and symptoms over time in the three different unemployment groups (fig 1).
The figure underscores that —with one exception-the early unemployed group always had the top position in unfavourable habits and symptoms, but it also draws attention to the fact that already at the outset of the study this early unemployed group was "worse off" regarding the outcome variables. The only significant linear changes in this suite of figures among the two unemployment groups (according to $\chi^{2}$ test for trend) was the increase in smoking among early unemployed men and the increase in excess alcohol consumption and somatic symptoms among late unemployed women. Besides, the reference group showed significant increases regarding excess alcohol (men), somatic symptoms (women), and psychological symptoms (men).

\section{Long term effects}

To analyse the change in habits and patterns in a multivariate model a logistic regression analysis was performed (table 2 ). 


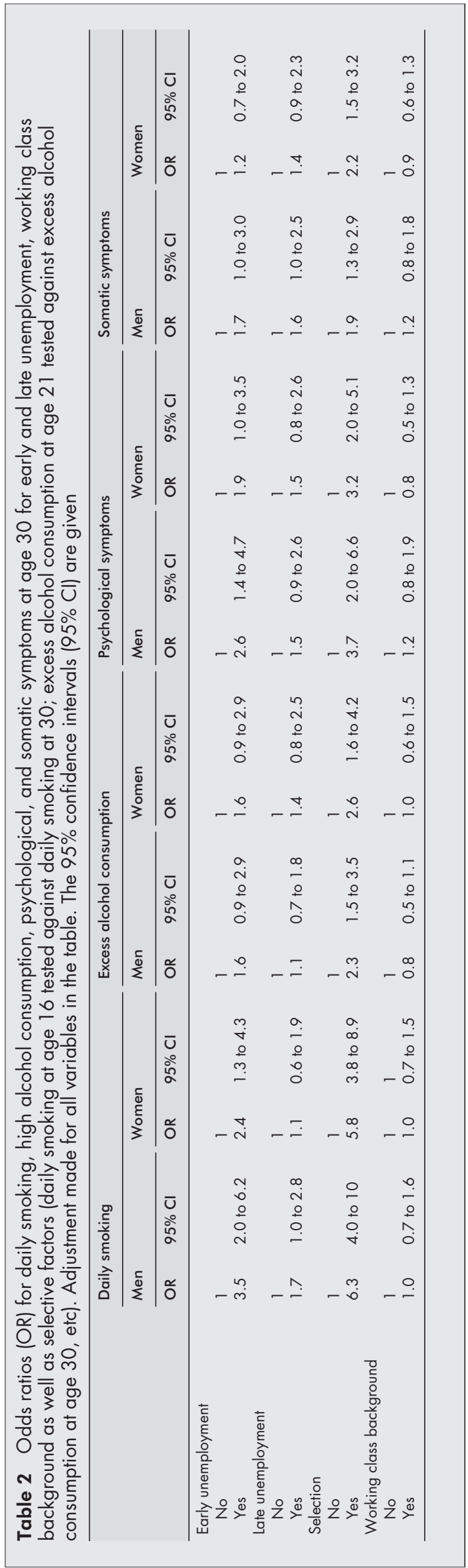

\section{Key points}

- Already at the beginning of the study those who later became early unemployed had the most unfavourable habits and symptoms.

- The best predictor of unfavourable health behaviour at age 30 was health behaviour at age 16.

- Even after controlling for possible confounders, including the initial health situation, early unemployment was significantly associated with unfavourable health behaviour and symptoms at age 30 .

- Unemployed tend to stay in "permanent impermanence", shifting between labour market programmes, studies, unemployment, and temporary jobs.

The model incorporated early and late unemployment and selection - that is, the value regarding symptoms and habits for each of the tested outcomes at the beginning of the study (age 16) on individual level. Besides, working class affiliation among parents was used as a background social indicator.

The table shows that "selection" (that is, behaviour and symptoms at the start of the study) was of crucial importance for all the studied dependent variables. The odds radios for these selection variables were highest regarding daily smoking and lowest regarding somatic symptoms. However, even after controlling for this an effect of unemployment remained. Early unemployment generated slightly more significant results and higher odds ratios than late unemployment. No influence of early or late unemployment was found on excess alcohol consumption or-among women only-on somatic symptoms. Working class background was of minor importance in the analysis.

\section{DISCUSSION \\ On method}

This study covers a long study period ( 14 years of follow up) with an extremely low attrition rate. The success was possible because of the Swedish system of personal identification numbers that makes it possible to find the address of any person in the country, because of a commitment to take care of the cohort through feedback of the results after every survey, and thanks to hard work. Problems with under-representation of, for example, unemployed and other marginalised groups are therefore low. Details of how this low drop out rate was attained have been presented elsewhere. ${ }^{21}$

\section{"...our study shows that early unemployment will not only affect the health of young people but can also have far reaching health consequences in adult age."}

The group studied included all pupils of a certain age group in the whole municipality and can be considered to be representative of young people in middle range industrial towns in Sweden. A test-retest study of the alcohol consumption and smoking showed highly reliable results. ${ }^{19}$

The unemployment levels in Sweden changed quite dramatically during the study period. During the first 10 years the peak youth unemployment rose from 3\% to about $8 \%$. From the beginning of the 1990s, the whole scenario changed; unemployment up to $20 \%$ was registered for young men (15\% for women) and the total rate for all ages went up to $10 \%$. So while the participants in the study changed from "young" to "adult", the relative magnitude of the unemployment to which they were exposed did not change very much.

Table 1 shows that with a definition of early long term unemployment as a total amount of six months or more of summarised unemployment during the first five years of observations $13 \%$ of the study population was included and the mean unemployment was around 10 weeks per year. Besides, 
unemployed people tend to stay in so called "permanent impermanence", a situation that is characterised by shifting between different labour market programmes, studies, unemployment, and temporary jobs. This situation, together with the increase of flexible employment (which means flexible in relation to wage, job security, working time, etc) on the new labour market increases the risk for similar negative health effects among the employed as among the unemployed. ${ }^{22-24}$ Furthermore, a majority of the cohort continued to secondary high school, which decreased their time of exposure to unemployment. As the time period was longer in the late unemployment group the limits were increased to 1.5 years.

The early unemployed group was defined irrespective of later unemployment. As a consequence of that the early unemployed group showed a higher degree of unemployment compared with the reference group also in the age $22-30$ years. Thus, the long term effects in the early unemployed group could therefore also be the result of late unemployment. However, other studies have shown a high degree of correlation between unemployment at two different time periods and a well documented effect of unemployment is future unemployment. ${ }^{23}$ To construct a group with only early unemployment would be to construct an artefact with no correspondence in real life. In the logistic regression analyses it was possible to adjust for late unemployment and in that way we tried to show the separate effect of early unemployment. Even though there was a correlation between early and late unemployment $(r<0.2)$, it was not big enough to introduce a problem of multicollinearity.

The cut off points for the dependent variables were chosen in two ways. For smoking we just differentiated between daily smoking or not. Regarding alcohol consumption there are some critical levels indicating harmful consumption, ${ }^{25}$ but they are not applicable to young persons (as in this case 16 years of age). There was also no natural cut off point regarding the used scales for symptoms. We decided to arbitrarily use the 75 th centile as a cut off point for all these measures.

\section{On results}

The study showed that unemployment in young age had long term effects on health and health behaviour among adult men and women. Even after control for health behaviour and symptoms as well as working class background at the beginning of the study and unemployment at the end of the study, the associations remained between early unemployment on one hand and smoking as well as psychological and somatic (men only) symptoms on the other hand at the age of 30 .

Our results are well in accordance with the few studies within the field, for example a Swedish long term follow up study which shows that unemployment, even when controlled for social, behavioural, work, and health related factors, is significantly associated with mortality up to 24 years after the registration of unemployment. ${ }^{15}$

The reasons for these longstanding associations remain unknown and require further studies. In some way or other, early unemployment seems to affect health behaviour and life circumstances in a way that makes the direct negative effects of early unemployment-which are well known from earlier research-become permanent in adult age even when the people are no longer unemployed. One explanation could be that in a situation of unemployment in young age it is difficult to make a positive reorientation (to stop smoking or to change cognitive stress related patterns). Health habits seem to be established in young age and may be difficult to change. ${ }^{26}$ However, early unemployment had no long term effect on excess consumption of alcohol despite earlier findings of correlations between unemployment and alcohol consumption in a short-term perspective. ${ }^{5}$ A possible explanation could be that smoking is more addictive and less sensitive for later changes than alcohol consumption.

Early unemployment had somewhat more negative long term effects on men. However, overall our results show much

\section{Policy implications}

- Creation of work opportunities for young men and women should be given a very high priority on the public health agenda.

- Work provides not only occupation but has also an important health promoting function in the transition from adolescence to adulthood.

- The unfavourable combination of hazardous health behaviour and early unemployment should be a challenge for the school: tobacco and alcohol consumption is shaped during the school years and the motivation for future studies is also founded during this period.

more similarities than differences between the men and the women. Even though smoking habits and psychological symptoms were more common among girls at the beginning of the study, the odds ratio for selection was in principle identical for the two sexes.

The possibilities of other explanations than early unemployment could never be ruled out. The early unemployment group was to a much higher degree negatively selected than the late unemployment group. Thus, early unemployment could be caused by a socially disadvantaged situation as a child, which also caused the poorer health situation at age 30 . However, the regression analysis speaks against the importance of an unfavourable social background when looking at long term health effects of unemployment. The regression analysis also speaks for an effect of early unemployment by its own, even after control for selection.

Our study gave support to both selective explanations as well as causal theories. Both daily smoking and high alcohol consumption and to a lesser degree also psychological and somatic symptoms were highly indicative of future unemployment. It seems strange that smoking at the age of 16 can be such a powerful predictor for future unemployment. It is hard to imagine that the employer's willingness to hire a person depends to such a high degree on whether or not he or she is a smoker. The correlation is probably attributable in part to the connections between smoking habits and education and/or other variables. ${ }^{27}$ The highest frequencies of smokers are found among short-term educated, and among them the risk of unemployment is also highest. Other studies, performed on adults with retrospective data on smoking habits, confirm our results that those who smoke have the highest risk of becoming unemployed even after control was made for the length of education and different socioeconomic variables. ${ }^{28}$

\section{The relation between unemployment and health}

The relation between exposure and outcome in a long term follow up is always cumbersome. Besides confounding factors there are a number of different ways in which unemployment may affect health. By adjusting for the entrance value of the different outcome measures (or to put it another way: by looking at the individual differences in behaviour and symptoms between the end and the beginning of the study instead of just looking at the behaviour at the end of the study) we can avoid the most obvious selection bias. Even when adjustment is made for selection, a number of significant associations persist, indicating that unemployment may affect health.

Regarding confounding factors, a problem is that many of the traditional indicators of social background are closely correlated with unemployment, not only as confounders but also as mediators. Short-term education for example, will increase the risk of unemployment. Adjusting for variables, which are parts of the causal chain, could lead to an underestimation of the possible effects of unemployment on the outcome.

We used working class background as a proxy for the social background situation, which also correlated with study motivation and unemployment experience in the family. ${ }^{29}$ It turned 
out that even if this variable is an important confounder in short-term follow up studies, ${ }^{30}$ it did not significantly affect the long term results.

As the definition of unemployment in this study was rather wide, it included a fairly broad population. This means that our results regarding early unemployment refer to something that will affect a proportionally large group in the community-between $10 \%$ and $15 \%$. Thus, our study shows that early unemployment will not only affect the health of young people but can also have far reaching health consequences in adult age.

\section{Conclusion}

Even after controlling for initial health behaviour and symptoms as well as working class background and late unemployment, early unemployment among young men and women showed a significant explanatory effect on smoking, psychological symptoms, and-among men only-somatic symptoms after a follow up of 14 years. No correlation was found between early unemployment and excess alcohol consumption. Thus, youth unemployment constitutes a significant public health problem, which to a certain extent remains to adult age.

\section{APPENDIX}

Have you now (or have you during the past 12 months had) troubles with

\begin{tabular}{llll}
\hline & No & Yes, slight problems & Yes, serious problems \\
\hline Headache, migraine & 0 & 1 & 2 \\
Cold, influenza & 0 & 1 & 2 \\
Cough & 0 & 1 & 2 \\
Genital discomfort & 0 & 1 & 2 \\
Gastritis, heartburn or gastric ulcer & 0 & 1 & 2 \\
Indisposition & 0 & 1 & 2 \\
Loss of weight & 0 & 1 & 2 \\
Diarrhoea & 0 & 1 & 2 \\
Constipation & 0 & 1 & 2 \\
Lack of appetite & 0 & 1 & 2 \\
Overweight & 0 & 1 & 2 \\
Pains in shoulders & 0 & 1 & 2 \\
Pains hands, elbows, legs or knees & 0 & 1 & 2 \\
Backache, pains in hip or sciatica & 0 & 1 & 2 \\
Inflammation of the bladder & 0 & 1 & 2 \\
Injury & 0 & 1 & 2 \\
Breathlessness & 0 & 1 & 2 \\
\hline
\end{tabular}

Have you now (or have you during the past 12 months had) troubles with

\begin{tabular}{lllll}
\hline & Never & Now and then & Relatively often \\
\hline Restlessness & 0 & 1 & 2 & 3 \\
Concentration difficulties & 0 & 1 & 2 & 3 \\
Anxiety & 0 & 1 & 2 & 3 \\
Worries & 0 & 1 & 2 & 3 \\
Palpitation of the heart & 0 & 1 & 2 & 3 \\
Sleeping problems & 0 & 1 & 2 & 3 \\
Depression & 0 & 1 & 2 & 3 \\
\hline
\end{tabular}

\section{Authors' affiliations}

Anne Hammarström, Urban Janlert, Department of Public Health and Clinical Medicine, Umeå University, Sweden

\section{REFERENCES}

1 Winefield $\mathbf{A H}$. Unemployment: its psychological costs. In: Cooper $\mathrm{CL}$ Robertson IT, eds. International review of industrial and organizational psychology. New York: Wiley, 1995: 169-212.

2 Warr P. Work, unemployment and mental health. Work, unemployment and mental health. Oxford: Clarendon Press, 1987.

3 Morrell SL, Taylor RJ, Kerr CB. Jobless. Unemployment and young people's health. Med J Aust 1998;168:236-40.

$4 \mathrm{Kasl}$ SV, Jones BA. The impact of job loss and retirement on health. In: Berkman LF, Kawachi I, eds. Social epidemiology. Oxford: Oxford University Press, 2000: 118-36.

5 Janlert U, Hammarström A. Alcohol consumption among unemployed youths: results from a prospective study. Br J Addict 1992;87:703-14.

6 Montgomery SM, Cook DG, Bartley M, et al. Unemployment, cigarette smoking, alcohol consumption and body weight in young British men. Eur J Public Health 1998;8:21-7.

7 Hammarström A. Health consequences of youth unemployment. Public Health 1994;108:403-12.
8 Fergusson DM, Horwood L, Lynskey MT. The effects of unemployment on psychiatric illness during young adulthood. Psychol Med 1997;27:371-81

9 Winefield $\mathbf{A H}$, Tiggeman $M$, Winefield HR, et al. Growing up with unemployment. A longitudinal study of its psychological impact. London: Routledge, 1993

10 Morrell S, Taylor R, Quine S, et al. A cohort study of unemployment as a cause of psychological disturbance in Australian youth. Soc Sci Med 1994;38:1553-64.

11 Morrell S, Taylor R, Quine S, et al. A case-control study of employment status and mortality in a cohort of Australian youth. Soc Sci Med 1999:49:383-92.

12 Lewis G, Sloggett A. Suicide, deprivation, and unemployment: record linkage study. BM 1998;317:1283-6.

13 Fryer D. International perspectives on youth unemployment and mental health: some central issues. Journal of Adolescence 1997;20:333-42.

14 Moser KA, Goldblatt PO, Fox AV, et al. Unemployment and mortality: comparison of the 1971 and 1981 longitudinal study census samples. BM 1987:294:86-90.

15 Nylen L, Voss M, Floderus B. Mortality among women and men relative to unemployment, part time work, overtime work, and extra work: a study based on data from the Swedish twin registry. Occup Environ Med 2001;58:52-7.

16 Wadsworth MEJ, Montgomery SM, Bartley M. The persisting effect of unemployment on health and social well-being in men early in working life. Soc Sci Med 1999;48:1491-9. 
17 Hibell B, Jonsson E. En undersökning av elevers alkohol-, narkotikatobaks- och sniffningsvanor våren 1981. [An investigation into pupils' alcohol, narcotics, tobacco and sniffing habits in Spring 1981] [In Swedish]. Stockholm: Skolöverstyrelsen; 1982.

18 Thorslund M, Wärneryd B. Methodological research in the Swedish surveys of living conditions. Problems of measurement and data collection. Soc Indic Res 1985;116:77-95.

19 Hammarström A. Ungdomsarbetslöshet och ohälsa. Resultat från en tvåårsuppfölining. [Youth unemployment and ill-health. Results from a two-year follow up] [In Swedish, summary in English]. Stockholm: Karolinska Institute, 1986

20 ILO. Employment and unemployment statistics. Geneva: International Labour Office, 1954

21 Novo M, Hammarström A, Janlert U. Does low willingness to respond introduce a bias? - results from a socio-epidemiological study among young men and women. International Journal of Social Welfare 1999;8: 155-63.

22 Benach J, Benavides FG, Platt S, et al. The health-damaging potentialof new types of flexible employment: a challenge for public health researchers. Am J Public Health 2000;90:1316-17.
23 Hammarström A Janlert U. Does early unemployment and health status among young men and women affect their chances of later employment? Scand J Public Health 2000;28:10-15.

24 Novo M. Young and unemployed-does trade cycle matter for health? A studyof youngmen and women during times of prosperity and times of recession. Umeå: Umeå University, 2000.

25 Hollstedt C, Rydberg U. Hazardous alcohol consumption and early diagnosis of alcohol-linked disease. Läkartidningen 1981;78:795-9.

26 Emmons KM. Health behaviors in a social context. In: Berkman LF, Kawachi I, eds. Social epidemiology. Oxford: Oxford University Press, 2000:242-66.

27 Lee Al, Crombie IK, Smith WC, et al. Cigarette smoking and employment status. Soc Sci Med 1991;33:1309-12.

28 Waldron I, Lye D. Employment, unemployment, occupation, and smoking. Am J Prev Med 1979:5: 142-9.

29 De Gode M, Spruijt E, Maas C, et al. Family problems and youth unemployment. Adolescence 2000;35:587-601.

30 Hammarström A, Janlert U, Theorell T. Youth unemployment and ill health: results from a 2-year follow-up study. Soc Sci Med 1988;26: 1025-33. 